\title{
O PROCESSO DE AVALIAÇÃO PSICOLÓGICA no estado do Paraná
}

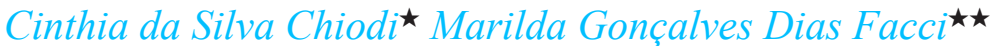

\begin{abstract}
Resumo
A avaliação psicológica das queixas escolares e a utilização dos testes psicológicos fazem parte da atuação do psicólogo escolar. Este artigo tem como objetivo apresentar os resultados de uma pesquisa realizada em relatórios de avaliação psicoeducacional elaborados por psicólogos, buscando compreender como a avaliação psicológica está sendo realizada pelos profissionais psicólogos no Estado do Paraná. Foram analisados 36 relatórios para encaminhamento de alunos de $5^{a}$ a $8^{a}$ séries para a Sala de Recursos. De maneira geral, pudemos constatar que 93,44\% dos psicólogos utilizam testes de inteligência, mas muitos deles também utilizam observações e analisam as atividades escolares para avaliar as queixas escolares, não se limitando a uma visão psicométrica. A partir dos fundamentos da Psicologia Histórico-Cultural, entendemos que a avaliação deve considerar as potencialidades dos alunos e deve ter como meta contribuir para que eles se apropriem do conhecimento cientifico elaborado pelos homens.

Palavras-chave: avaliação psicológica; processo ensino-aprendizagem; Psicologia Histórico-Cultural.

\section{Psychological eVAluation process In THe state of Paraná}

\begin{abstract}
The psychological evaluation of school complaints and the use of psychological tests are one of the roles of the school psychologist. Current analysis presents the results of a research retrieved from psycho-educational evaluation reports prepared by psychologists. The latter tried to understand the manner psychological evaluation was being undertaken by psychologists in the state of Paraná, Brazil. Thirty-six reports directing students of the 5th -8 th series of the junior high

\footnotetext{
^Psicóloga. Mestranda em Psicologia pela Universidade Estadual de Maringá. Atualmente trabalha como psicóloga da Escola de Educação Especial Roberto Farias da Silva e psicóloga escolar da Prefeitura Municipal de Tapira.

E-mail: cinthiachiodi@yahoo.om.br Araraquara - Universidade Estadual Paulista "Júlio de Mesquita Filho" e Pós-Doutorado pelo Instituto de Psicologia da Universidade de São Paulo. É professora do Departamento de Psicologia e Programa de Pós-Graduação em Psicologia da Universidade Estadual de Maringá. Endereço: Universidade Estadual de Maringá - Departamento de Psicologia. Av. Colombo, 5790 - Jardim Universitário. Maringá - PR. CEP: 87.020-900.

E-mail:mgdfacci@uem.br
}

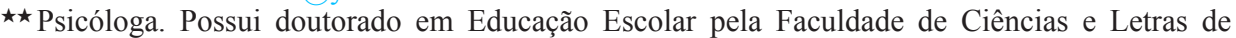


school to the Resource Room have been examined. Although intelligence tests were employed by $93.44 \%$ of psychologists, many made use of observations and analyzed school activities to assess school complaints, without limiting themselves to psychometrics. Taking Historical and Cultural Psychology as a foregrounding point of view, it may be said that evaluation may take into account the students' potentialities and should contribute towards their appropriation of the scientific knowledge fabricated and accumulated by all.

Keywords: psychological evaluation; teaching-learning process; Historical and Cultural Psychology.

O fracasso escolar é um dos problemas que têm preocupado vários pesquisadores. Para os psicólogos que atuam no contexto educacional, principalmente nos primeiros anos de escolarização, uma das queixas mais frequentes se refere a crianças que não conseguem se apropriar da leitura, da escrita ou dos conteúdos matemáticos. Muitas vezes esses profissionais são solicitados a avaliar e apontar as causas de tais dificuldades, assim como a auxiliar a escola no estabelecimento de alguns procedimentos pedagógicos que poderiam contribuir para a aprendizagem do aluno.

De acordo com Patto (1990), os psicólogos tiveram como função, no final do século XIX, medir inteligência. Através de resultados dos testes psicológicos, explicavam-se as diferenças individuais e se podia afirmar a existência de alunos aptos e não aptos para aprender. Segundo Lunt (1994), o movimento de avaliação e testagem começou no início do século XX, especialmente pelos testes de Quociente de Inteligência (QI), que ainda são o instrumento mais utilizado para avaliar alunos com dificuldades no processo de escolarização. Isso pode ser observado em pesquisa realizada por Facci, Roma e Silva (2007) que, ao analisarem artigos publicados em sete periódicos de Psicologia, no período de 1980 a 2006, constataram os testes psicológicos mais mencionados pelos autores para fazer avaliação psicológica: Matrizes Progressivas de Raven, Escala de Inteligência Weschler, Teste das Pirâmides Coloridas de Pfister, Bender Gestalt Test, Escala de Maturidade Columbia e Teste de Desempenho Escolar.

Tal prática continua sendo uma marca da Psicologia Escolar também no Paraná. Em pesquisa realizada por Lessa e Facci (2011), acerca da atuação dos psicólogos escolares no ensino público no Estado do Paraná, a autoras constataram que $87,4 \%$ dos participantes fazem avaliação psicológica e que muitas vezes estes são contratados principalmente para desenvolver essa atividade. Os testes de inteligência são os instrumentos mais utilizados no caso da avaliação, mas também outras formas de avaliação têm sido propostas, conforme se verá neste artigo, que tem como objetivo apresentar os resultados de uma pesquisa realizada em relatórios de avaliação psicoeducacional elaborados por psicólogos, buscando compreender como a avaliação psicológica está sendo realizada pelos profissionais no Estado do Paraná. 
Para a apresentação dessa temática, num primeiro momento nos deteremos em discorrer sobre a avaliação psicológica na escola, em seguida trataremos do processo de avaliação na perspectiva da Psicologia Histórico-Cultural, que tem sustentado discussões que se têm realizado na área da Psicologia Escolar; finalmente, apresentaremos dados da pesquisa realizada com psicólogos do Paraná.

\section{A aVAliaÇão psicológica na escola}

Segundo Primi (2010), a avaliação psicológica é uma atividade complexa de "busca sistemática de conhecimento a respeito do funcionamento das pessoas, de tal forma a poder orientar ações e decisões futuras". Essa avaliação contém instrumentos "que são meios padronizados de se obter amostras/indicadores comportamentais que irão revelar diferenças individuais nos construtos, traços latentes ou processos mentais subjacentes" (PRIMI, 2010, p. 26).

A área de avaliação psicológica tem tido grande crescimento no Brasil nos últimos 20 anos, conforme refere Primi (2010). Instrumentos de medida são revistos e padronizados, assim como são criadas metodologias de avaliação que, segundo o autor, constituem-se como avanços significativos na área. A grande produção nessa área e a preocupação ética com o uso dos instrumentos específicos para o psicólogo levaram o Conselho Federal de Psicologia (CFP) a instituir, em 2003, o Sistema de Avaliação dos Testes Psicológicos (SATEPSI), no sentido de acompanhar o desenvolvimento da avaliação psicológica. Conforme Ayach e Correa (2010), tem havido grande esforço do CFP para "garantir o rigor teórico e metodológico no uso da avaliação psicológica, bem como no emprego de instrumentos válidos e precisos".

Tavares (2010) afirma que, historicamente, no final do século XIX e início do XX o, surgimento da Psicologia e a avaliação psicológica se confundem, haja vista que pesquisadores como Francis Galton (1822-1911), Alfred Binet (18571911), Theophile Simon (1857-1911), James McKeen Castell (1860-1940), preocupados em estudar as diferenças individuais, envidavam esforços no sentido de fazer com que a Psicologia ganhasse status de ciência. "As contribuições desses autores são exemplos da relação indissociável entre o estabelecimento da Psicologia como ciência e profissão e o desenvolvimento dos testes, entre outros procedimentos de avaliação psicológica" (TAVARES, 2010, p. 32). Mindrisz (1994) comenta que a investigação objetiva e quantitativa das diferenças individuais configura-se como o campo de estudo da Psicometria.

O biólogo inglês Francis Galton contribuiu expressivamente para o estabelecimento da Psicologia das Diferenças Individuais. Ele foi o primeiro a aplicar os princípios evolucionistas de variação, relação e adaptação para o estudo dos traços psicológicos humanos. Era considerado também o fundador do movimento eugênico e tinha grande interesse pelo estudo da hereditariedade. Segundo Moysés e Collares (1997), a transferência de pressupostos da teoria darwinista - o evolucionismo e a seleção natural - para o entendimento de fenômenos que ocorrem nas sociedades humanas, constitui o terreno onde se fundamentam as teorias que tentam justificar a discriminação entre os homens. Nesse aspecto, 
não se pode esquecer que Francis Galton, o idealizador dos testes de inteligência, tinha como objetivo a seleção dos mais capazes para o aprimoramento da espécie humana. Desse modo, é possível observar que os testes de inteligência já nasceram comprometidos em discriminar uma classe específica e pouco preocupados em auxiliar os alunos no processo ensino-aprendizagem.

Gomes (2004) afirma que em 1890, James Mckeen Catell escreveu um artigo no qual o termo testes mentais foi usado pela primeira vez; mas a grande virada na medida dos processos mentais superiores aconteceu na França, no final do século XIX e início do XX, com a pesquisa do psicólogo francês Alfred Binet, preocupado em analisar o Quociente de Inteligência (QI). ${ }^{1}$ Os estudos desse psicólogo situam-se no período em que nos países europeus, principalmente na França, houve a democratização do ensino, a institucionalização do ensino básico obrigatório, ou seja, ocorreu todo um projeto nacional com o objetivo de que as crianças aprendessem efetivamente e na escola fosse formado o novo homem. Assim, seria essa escola pública, organizada conforme os princípios burgueses, que viria assegurar e defender os interesses da classe dominante, com o objetivo de formar o seguidor da ordem e da moral exigidas para a manutenção do capitalismo. Foi nesse contexto que a preocupação com aqueles que fracassavam na escola se fez presente, contribuindo para o desenvolvimento da psicometria. Neste sentido, segundo Patto (1984), o cálculo do QI foi a medida das aptidões humanas que mais fez sucesso na história da Psicologia, e esse sucesso não foi casual, pois a quantificação, quase mágica, realizava o sonho da sociedade industrial capitalista de poder pautar-se por um critério numérico e objetivo para classificar seus membros.

No Brasil, a formação do psicólogo se deu a partir de 1962 e o profissional era formado principalmente como um técnico. A psicometria e o modelo clínico guiavam a atuação do psicólogo escolar (PATTO, 1984). Carvalho e Marinho-Araújo (2009) referem que, nas décadas de 1970 e 1980, surgiram duras críticas a essa forma de ação da Psicologia na Educação. Especialmente a partir da década de 1980, diante das condições de vida deterioradas do povo brasileiro, causadoras de sofrimento psíquico, os psicólogos não puderam mais manter-se indiferentes a essa realidade. Rompendo com a tradição individualista, naturalizante e patologizante da ciência e das práticas psicológicas, começou a surgir uma psicologia escolar crítica, que tinha o objetivo de compreender os determinantes históricos e sociais da formação e da atuação do psicólogo escolar.

No caso das produções em Psicologia Escolar, Meira (2000) ressalta, ao final da década de 1970 e início de 1980, que começaram a ser criadas condições para uma revisão crítica da trajetória da Psicologia educacional/escolar no Brasil com a defesa da tese de Maria Helena Souza Patto, publicada, posteriormente, no livro Psicologia e Ideologia - uma introdução crítica à Psicologia escolar. Patto (1984) faz uma leitura crítica das relações da escola com a sociedade e com a Psicologia Escolar, no marco de uma formação social capitalista. Teve início, assim, uma psicologia que buscava fazer a crítica ao modelo clínico e à naturalização e patologização das queixas escolares, compreendidas como problemas de aprendizagem ou de comportamento. Desse modo, à medida que se 
avançava na crítica aos pressupostos do modelo clínico de atuação e à produção do fracasso escolar, tornava-se mais do que evidente a necessidade de uma redefinição dos processos tradicionais de avaliação e diagnóstico.

Souza (2007), nesta linha de uma intervenção crítica, afirma que a escola deve ser incluída na investigação e na intervenção da queixa, ampliando a compreensão da construção desta. Machado (2000) também afirma que se tornou "natural", por meio da psicometria, a crença na possibilidade de medirmos a inteligência e a capacidade individual das pessoas como se fôssemos constituídos fora das relações sociais. A padronização dos testes psicológicos, segundo a autora, tem desconsiderado as desigualdades sociais e culturais existentes em nosso sistema capitalista. Souza e Machado afirmam que a queixa escolar é constituída por uma história coletiva e que a avaliação implica buscar quanto é possível alterar a produção dessa queixa. Segundo os autores, uma proposta bem fundamentada para uma avaliação adequada envolve avaliar todas as condições da criança, não se analisando somente o que esta não tem, não sabe, mas entendendo principalmente o que ela sabe fazer, o que gosta de fazer e o que pode aprender a partir de então.

Autores como Souza (2007) e Machado (2000), por exemplo, questionam a utilização de testes para avaliar as queixas escolares. Patto (1997) também engrossa esse rol de críticas e questiona os conteúdos dos testes e a definição de inteligência e de personalidade em que estes se baseiam, o critério estatístico, de padronização e da situação de testagem propriamente dita; assim como a teoria de conhecimento a partir da qual os testes são gerados. Sendo assim, as críticas na área da Psicologia Escolar, nas explicações para o fracasso escolar, precisam superar uma atuação fundamentada na visão psicométrica, na qual se elaboram laudos psicológicos baseados na Teoria da Carência $\mathrm{Cultural}^{2}$ e no modelo clínico de atuação no atendimento à queixa escolar.

No Brasil, a partir da década de 1990, começou a ser discutida outra forma de avaliação, denominada avaliação dinâmica (mediada ou assistida). Sobre essa forma de avaliação, Linhares, Escolano e Enumo (2006, p. 16-17) afirmam:

Originou-se de concepções teóricas sobre a plasticidade da cognição humana e da necessidade prática de encontrar novas medidas de diagnóstico para crianças que não se saiam bem em testes convencionais. Os conceitos de "zona de desenvolvimento proximal" (ZDP), de Vygotski, e a "teoria de aprendizagem mediada" ou da "experiência da aprendizagem mediada"(MLE), de Feüerstein, formam a base conceitual para a elaboração da avaliação assistida ou dinâmica" [...]

De acordo com Lunt (1994, p. 232), avaliação mediada "[...] envolve uma interação dinâmica entre examinador e aluno (examinado) com mais ênfase sobre o processo do que sobre o produto da aprendizagem" (grifos do autor). Interessa, nesse aspecto, compreender como a criança aprende ao invés de avaliar "o quê" ela já aprendeu. 
A definição de Linhares (1995, p. 24), que também propõe esse tipo de avaliação assistida, está redigida da seguinte forma:

[...] um conjunto de estratégias instrucionais utilizadas durante o processo de avaliação, a fim de garantir o fornecimento de ajuda, melhorando as condições a situação de avaliação, para que o examinando possa revelar o seu desempenho potencial e possa atingir um grau crescente de autonomia em situações de resolução de problemas.

Podemos afirmar, nesse aspecto, que a avaliação é mediada pelo examinador, que fornece pistas e orienta o sujeito na realização das atividades. O conceito de aprendizagem mediada, de acordo com Linhares (1995), teve implicações significativas na área de avaliação do desempenho intelectual; no entanto, conforme dados coletados por Facci; Roma e Silva (2007), após levantamento bibliográfico de sete periódicos nacionais de Psicologia, constataram que, do total de artigos (2.488) apenas 65 , ou $2,61 \%$, abordavam o tema de avaliação psicológica na escola, e destes, somente cinco mencionavam autores da Psicologia HistóricoCultural. A seguir, trataremos da avaliação psicológica nesta perspectiva teórica.

\section{O MÉTODO INSTRUMENTAL}

Os pressupostos da Psicologia Histórico-Cultural, elaborados a partir dos estudos de Lev Semenovitch Vigotski (1896-1934), Alexander Romanovich Luria (1902-1977) e Alexei Nikolaievich Leontiev (1904-1979) trouxeram novos elementos para pensar a relação entre desenvolvimento e aprendizagem, o que acabou por interferir na forma de entender a avaliação psicológica. Vigotski (1996) propõe uma abordagem histórica do psiquismo humano, buscando construir uma psicologia fundamentada no marxismo e partindo de uma filosofia que concebe o homem como ser histórico. Neste sentido, Vigotski ressalta a necessidade de estudar os processos psicológicos do ser humano em sua historicidade, considerando-se a forma e o momento de sua intervenção no processo de desenvolvimento. Ele alerta sobre o fato de que o investigador precisa buscar a essência do fenômeno dentro de um contexto histórico determinado. Se pensarmos nas dificuldades do processo de escolarização, o psicólogo necessita analisar as condições histórico-sociais que produzem essa dificuldade no aluno e, antes disso, ter clareza da função da escola.

Saviani (2003) afirma que cabe à escola socializar os conhecimentos produzidos pelos homens. O autor, a partir da base marxista, compreende, assim como Leontiev (1978), que para o indivíduo se humanizar é necessário que ele se aproprie das objetivações humanas, ou seja, que se aproprie dos vários conhecimentos produzidos pelos homens no decorrer da história, tornando singular esse saber. O homem nasce hominizado, conforme afirma Leontiev, e é a apropriação da cultura que levará esse homem a se diferenciar dos animais. Vygotski e Luria (1996), neste sentido, entendem que conforme vai se apropriando da cultura a criança vai se tornando reequipada, mas desenvolvida no aspecto cognitivo. 
Vigotski (2000), ao tratar da relação entre desenvolvimento e aprendizagem, afirma que esta impulsiona o desenvolvimento. Para o autor russo, a apropriação do conhecimento científico provoca o desenvolvimento das funções psicológicas superiores: a atenção concentrada, memória lógica, abstração e outras. Se em uma avaliação tradicional, calcada na psicometria, compreendia-se que a maturação era responsável pela complexificação das funções psicológicas elementares, na perspectiva da Psicologia Histórico-Cultural compreende-se que elas são formadas, primeiro, entre as pessoas, na coletividade, para depois serem internalizadas. O desenvolvimento ocorre por meio das mediações realizadas com a criança, seja por uma criança mais experiente, seja por um adulto. Antes de se_tornarem internalizadas, as funções demandam uma tomada de consciência e voluntariedade como condição para se desenvolverem.

Luria (1981) compreende que as funções psicológicas superiores devem ser tomadas como sistemas funcionais que são formados ao longo do desenvolvimento histórico, baseados em métodos e meios culturais, implicando nas formas fundamentais da atividade consciente. Neste sentido, todo comportamento é mediado por instrumentos - que modificam a realidade externa - e signos - que transformam a realidade interna do indivíduo, como são, por exemplo, os casos da linguagem e da escrita. Os instrumentos ou ferramentas utilizados para transformarem a natureza, produto da prática social, provocaram e provocam o desenvolvimento do funcionamento mental. Essas ferramentas, além de provocarem mudança na realidade externa, também agem sobre o homem, efetuando uma mudança em sua condição psíquica. Destarte, a forma como o aluno pensa, raciocina, memoriza os conteúdos tem relação com a evolução biológica desde os animais até o ser humano. O mesmo acontece com a evolução histórico-cultural da humanidade, que resultou na transformação gradual do homem primitivo no homem cultural moderno, e com o desenvolvimento ontogenético, ou seja, a evolução do desenvolvimento individual de uma personalidade específica do indivíduo em suas várias fases de desenvolvimento (VYGOTSKY; LURIA, 1996).

Para Vigotski (2000), existem dois níveis de desenvolvimento: o real, que se remete a atividades que a criança já internalizou e que consegue realizar sozinha e a zona de desenvolvimento próximo, no qual a criança realiza as atividades com auxílio. As avaliações baseadas em testes de inteligência, que ocorrem de forma estática, levam em conta somente o que está no nível de desenvolvimento real e na Escola de Vigotski considera-se que é necessário avaliar o que se encontra no nível de desenvolvimento próximo do aluno, utilizando-se de recursos mediadores para fazer a avaliação.

Vygotsky e Luria (1996), ao tratarem da avaliação do desenvolvimento das funções psicológicas superiores dos indivíduos, mostram quanto os mediadores e os estímulos artificiais criados pelos homens podem auxiliar na avaliação do desenvolvimento cognitivo dos indivíduos. Se o psicólogo, ao fazer um teste de memória, utilizar, por exemplo, cartões com desenhos diversos para a realização da atividade, o uso desse recurso mediador pode auxiliar o indivíduo nesse processo complexo de memorização. Tal prática de avaliação fica muito evidente em vários experimentos realizados por Luria (2008). 
O método instrumental, elaborado por Vigotski, supera a concepção inatista, ambientalista e interacionista do desenvolvimento humano, pois como afirmamos, as funções psicológicas superiores configuram-se como produto da atividade cerebral e têm uma base biológica, mas, fundamentalmente, são resultantes da interação do indivíduo com o mundo, interação essa mediada pelos objetos construídos pelos homens. Para Vygotsky e Luria (1996) o nível intelectual da criança pode ser avaliado por sua capacidade de utilizar os recursos mediadores, criados pelos homens, na realização das atividades cognitivas propostas. Os autores afirmam:

Acapacidade de fazeruso de ferramentas torna-seumindicador do nível de desenvolvimento psicológico. Podemos afirmar com toda a segurança que esses processos de aquisição de ferramentas, juntamente com o desenvolvimento específico dos métodos psicológicos internos e com a habilidade de organizar funcionalmente o próprio comportamento, é que caracterizam o desenvolvimento cultural da mente da criança (VYGOTSKY; LURIA, 1996, p. 183).

Segundo os autores, os testes psicológicos geralmente avaliam somente o grau de conhecimento da criança, o que está em seu nível de desenvolvimento real, e não as suas potencialidades. Neste sentido, Vygotski (1995) destaca a importância de na avaliação fazer uma análise do processo e não do objeto, ou seja, compreender como a criança realiza uma determinada atividade, ou que recursos mediadores ela utiliza, por exemplo. Não interessa somente se ela acertou ou não a questão proposta; o que tem de ser analisado é como ela chega a essa resposta, que relações ela estabelece para concluir a atividade.

Outro fator destacado pelo autor refere-se à análise explicativa, e não descritiva, não se ficando somente no relato do que a criança não consegue, mas buscando-se compreender a causa de ela apresentar determinados comportamentos (VYGOTSKI, 1995). Muitas vezes os psicólogos, nos laudos que elaboram, preocupam-se em descrever o comportamento da criança, relatando o que consegue ou não fazer, mas não explicam por que isto acontece. A análise deve revelar e manifestar as relações e nexos dinâmico-causais. É preciso compreender e analisar as relações internas dos fatos, e não somente suas manifestações.

O terceiro ponto referido por Vigotski (1995) em relação ao método instrumental diz respeito à análise genética, que volta ao ponto de partida e restabelece todos os processos de desenvolvimento, para compreender como se originou e desenvolveu a queixa escolar, no caso da avaliação dos problemas de escolarização, e não simplesmente descobrir ou explicar as novas formas de conduta. As dificuldades apresentadas pelas crianças geralmente são construídas na história do seu processo de escolarização. Uma das maiores dificuldades apontadas por Vygotski (1995, p. 135) em uma análise genética é "[...] compreender, mediante processos de conduta artificialmente organizados e provocados por via experimental, o processo natural de desenvolvimento na vida real". A grande dificuldade está em transferir os dados analisados, por exemplo, do comportamento infantil, do 
esquema experimental para a vida real, para situações que não foram provocadas intencionalmente pelo experimentador em laboratório. Vigotski explica que estudar alguma coisa historicamente "... significa estudá-la em movimento. Esta é a exigência fundamental do método dialético. Quando em uma investigação se abarca o processo de desenvolvimento de algum fenômeno em todas suas fases e relações, desde que surge até que desaparece, isso implica pôr em manifesto sua natureza, conhecer sua essência..." (VYGOTSKI, 1995, p. 68).

Retomemos alguns aspectos trabalhados por autores da Psicologia Histórico-Cultural. Conforme destacam Facci, Eidt e Tuleski (2006), uma avaliação psicoeducacional adequada necessita contemplar uma análise do desenvolvimento infantil de um modo prospectivo, indicando noções e conceitos que estão no nível de desenvolvimento próximo. No processo de avaliação o psicólogo deve considerar a criança como escolar, pois o método instrumental estuda os processos de desenvolvimento natural e de educação como um processo único. A educação influi em alguns processos de desenvolvimento e, principalmente, reestrutura as funções do comportamento em toda a sua amplitude.

Considerando o exposto, nesta perspectiva de avaliação fundamentada na Psicologia Histórico-Cultural, compreendemos que uma avaliação psicométrica, sem utilizar recursos mediadores e sem fazer uma análise da produção da queixa escolar no aluno, terá poucos elementos capazes de contribuir para uma prática que possibilite ao aluno apropriar-se do conhecimento.

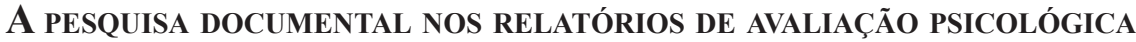

Na pesquisa documental a análise dos relatórios teve como objetivos identificar quais os instrumentos utilizados pelos psicólogos para o encaminhamento dos alunos de $5^{\mathrm{a}}$ a $8^{\mathrm{a}}$ série do Ensino Fundamental para a Sala de Recursos e analisar quais aspectos foram avaliados pelos psicólogos para que houvesse esse encaminhamento. Dessa forma, tivemos a intenção de conhecer a forma como a avaliação psicológica está sendo realizada no Estado do Paraná e de compreender até que ponto essa avaliação contribui para o processo ensino-aprendizagem.

A Sala de Recursos faz parte da modalidade de ensino da Educação Especial e configura-se como um tipo de apoio especializado às crianças com necessidades educacionais especiais. No Paraná o seu funcionamento é regulamentado pela Deliberação n. ${ }^{\circ}$ 02/03, editada em 02/06/03 (PARANÁ, 2003). No caso do encaminhamento de alunos de Classe Especial ou Escola Especial exige-se que a avaliação seja realizada por uma equipe multiprofissional que inclua o psicólogo.

Nos cursos de formação para a realização de avaliação psicoeducacional propostos pela Secretaria de Estado da Educação - Departamento de Educação Especial - existem algumas orientações para esse processo de avaliação. A avaliação deve conter informações tanto pedagógicas como psicológicas. Deve-se fazer uma investigação da linguagem, da escrita e dos conceitos matemáticos. No caso da avaliação psicológica, a orientação é que os psicólogos utilizem testes de inteligência, e neste caso, o teste indicado é o Wechsler Intelligence Scale 
for Children - WISC-III, e na ausência deste, o teste Matrizes Progressivas de Raven. Em qualquer caso, sugere-se que se faça uma avaliação em contexto, não se limitando exclusivamente aos testes. Essas informações são importantes para contextualizar como os alunos são avaliados pelos psicólogos no Estado.

Para a coleta de dados sobre a forma de avaliação realizada pelos profissionais entramos em contato com Núcleos Regionais de Educação do Paraná. ${ }^{3} \mathrm{O}$ Estado está dividido em 32 núcleos; destes, selecionamos 16, de acordo com a subdivisão geográfica do Estado. Nossa intenção era coletar dados de diversas regiões, por isso entramos em contato com $50 \%$ desses núcleos. Solicitamos àqueles núcleos com os quais foi possível estabelecer contato por meio de e-mail ou via telefone que nos enviassem relatórios de avaliações psicológicas para encaminhamento de alunos para a sala de recursos, de $5^{\mathrm{a}}$ a $8^{\mathrm{a}}$ série, entre os anos de 2008 e 2010 . Somente dez núcleos responderam à solicitação, e destes, foram obtidos 36 relatórios.

$\mathrm{Na}$ análise dos relatórios buscamos coletar os seguintes dados: 1) informações sobre motivos ou queixas de encaminhamento para a realização da avaliação psicológica, 2) procedimentos utilizados durante o processo de avaliação; 3 ) testes psicológicos utilizados; 4) pareceres psicológicos emitidos pelos psicólogos nos relatórios, buscando-se constatar o diagnóstico que eles fizeram em relação ao desempenho dos alunos; 5) encaminhamento dos alunos após a realização da avaliação psicológica; 6) sugestões para o trabalho com os alunos avaliados, procurando-se identificar as propostas relatadas pelos psicólogos que poderiam contribuir para superar as dificuldades detectadas no aluno no processo de avaliação.

Quanto aos motivos dos encaminhamentos dos alunos para avaliação psicológica, pode-se observar que a maioria dos encaminhamentos foram decorrentes das queixas de dificuldades de aprendizagem: dos 36 relatórios, $12(33,3 \%)$ apresentaram essa queixa. Um dado importante mostra que a mesma quantidade de relatórios - doze $(33,33 \%)$ - não explicitaram qual era o motivo da avaliação, demonstrando, assim, a falta de informações ou mesmo a imprecisão das dificuldades observadas nos alunos que foram encaminhados para avaliação.

No tocante às queixas escolares, Machado (2000) destaca que as ideias de "falta", de "carência", de "doença" e de "anormalidade" dominam a formulação das queixas com relação às inúmeras crianças que são encaminhadas pelas escolas para avaliação psicológica. Neste contexto, é possível perceber, segundo a autora, que as ideias acabam ganhando vida própria, pois muitas vezes o psicólogo se depara com queixas que são depositadas nos indivíduos - configuradas em "distúrbios de aprendizagem", "desnutrição", por exemplo - ou mesmo nos pais, apresentando a justificativa de que a "família é desestruturada" e por isso que o aluno não aprende, como se as causas dessas queixas não tivessem sido produzidas historicamente. A autora questiona a relação causa-efeito que muitas vezes é estabelecida entre problemas familiares ou emocionais e a capacidade de aprender. É importante, neste sentido, que a escola forneça informações iniciais que realmente demonstrem o que o aluno consegue e não consegue realizar na sala de aula. Esse seria o ponto inicial para começar a avaliação. 
Quanto aos procedimentos utilizados na avaliação psicológica, constatouse que o uso do teste psicológico formal psicométrico ainda é o instrumento mais utilizado para avaliar a inteligência humana, pois 34 relatórios $(93,44 \%)$ mencionaram o uso do teste formal. ${ }^{4}$ Neste sentido, Machado (2000) afirma que na sociedade capitalista tornou-se natural aquilo que é historicamente determinado. Dessa maneira, passou a ser natural encaminhar uma criança para um psicodiagnóstico do que ser descoberto algum atributo individual como justificativa para o fracasso escolar, ou seja, para justificar as dificuldades de aprendizagem apresentadas pelos alunos. Assim, a história desse olhar que procura culpar o sujeito se oficializou com o desenvolvimento das ciências humanas no século XIX, cujos argumentos isentavam a desigualdade social, inerente a esse sistema, da responsabilidade pelas diferenças sociais. Vimos, conforme Tavares (2010), que a Psicologia se consolidou utilizando-se dos testes. Machado (2000) informa que se tornou natural e legalmente instituída a crença na possibilidade de se medir a inteligência e a capacidade individual das pessoas como se elas fossem constituídas fora das relações sociais.

Em 21 relatórios $(58,33 \%)$ constatou-se que os psicólogos realizam observações durante o processo de avaliação e dez $(27,77 \%)$ fazem análise da atividade escolar e realizam anamnese com os pais, fugindo à exclusividade de aplicação dos testes para avaliar a capacidade cognitiva dos alunos. Somente cinco $(13,88 \%)$ analisam o histórico escolar, detendo-se mais nas dificuldades atuais dos alunos. Se considerarmos o que propõe Vygotski (1995) sobre o método instrumental e a importância de analisar a origem da constituição dos fatos, poderemos afirmar que o processo de constituição da queixa escolar foi pouco explorado pelos profissionais.

De modo geral, podemos ver que diversos psicólogos buscam fazer a avaliação no contexto e, mesmo aplicando testes, não se detêm apenas nestes instrumentos, fugindo, de certa forma, à "tirania" do teste do QI, conforme escreve Mindrisz (1994). Com relação aos testes psicológicos utilizados, 25 relatórios $(69,44 \%)$ não o, o que talvez se deva ao fato de a Secretaria de Educação do Paraná sugerir que os psicólogos não informem o teste psicológico utilizado no processo de avaliação. Como os testes sugeridos por essa Secretaria são o WISC III e, na ausência deste, o Raven, podemos concluir que, provavelmente, são esses os testes utilizados.

A maioria dos pareceres emitidos pelos psicólogos revela uma classificação dos alunos quanto ao desempenho cognitivo. Dos documentos analisados, 24 relatórios $(66,66 \%)$ expressaram que os alunos apresentavam desempenho abaixo da média do esperado para sua idade cronológica e experiência. Assim sendo, Mindrisz (1994) e Machado (2000) afirmam que o quociente de inteligência, resultado obtido nos testes de inteligência, passou a ser critério fundamental não só para a caracterização e classificação da deficiência mental, mas também para a predição do sucesso e do fracasso escolar. Apesar de alguns estudiosos da área da deficiência mental como Mindrisz (1994), Machado (2000), Moysés e Collares (1997), Calejon e Beatón (2002), Patto (1997), terem realizado esforços para relativizar o valor do QI como um critério determinante da deficiência mental, esse critério se configurou como uma herança adquirida no próprio percurso his- 
tórico dos testes de inteligência. Esses testes continuaram mantendo sua posição hegemônica com relação ao estabelecimento da definição de deficiência mental, e é isso o que podemos comprovar com tais relatórios, pois, conforme o resultado obtido nos testes psicológicos, os alunos são encaminhados para a Sala de Recursos. Um ponto interessante a analisar é que nem sempre o aluno que apresenta dificuldades no processo de escolarização tem um QI rebaixado, pois vimos que 12 alunos (33,33\%) apresentaram um QI dentro ou acima da média. Isto nos leva a concluir que o não-aprender não estava relacionado a um déficit cognitivo.

Causa preocupação o fato de alunos diagnosticados com distúrbios de aprendizagem, conforme constatamos em 14 relatórios (38,8\%). Com a expansão de explicações para o não aprendizado centrando-se nesse aspecto e conduzindo à medicalização, muitos psicólogos e professores estão deixando de analisar como ocorre o processo ensino-aprendizagem e retornando a fatores biológicos para explicar o não aprender. Moysés e Collares (1997) e Zucoloto (2007) denunciam que continua existindo uma patologização dos problemas que ocorrem no processo ensino-aprendizagem, conduzindo à explicação do fracasso escolar como decorrente de disfunções neurológicas, como distúrbios de aprendizagem, hiperatividade e dislexia. Quando se coloca no aluno ou no aspecto biológico a causa dos problemas de escolarização, não se considera, conforme Vygotski (1995), que as funções psicológicas superiores são desenvolvidas na coletividade, por meio da apropriação da cultura, e necessitam de mediações para serem desenvolvidas.

Quanto ao encaminhamento dos alunos após a realização da avaliação psicológica, pudemos constatar que 32 dos 36 relatórios sugeriram o encaminhamento dos alunos para a Sala de Recursos. Isto, de certa forma, é coerente com o recorte que fizemos na pesquisa, pois solicitamos aos Núcleos de Educação que nos enviassem relatórios de alunos que tivessem sido encaminhados para Sala de Recursos; no entanto, um dado relevante refere-se ao fato de 20 dos 36 alunos avaliados $(55,5 \%)$ terem sido encaminhados para atendimento psicoterápico e 16 alunos $(44,4 \%)$ terem sido encaminhados para avaliação neurológica. Estes dados demonstram que o viés patologizante ainda está presente nas explicações acerca do fracasso escolar, influenciado, principalmente, por uma visão ideológica fundamentada no liberalismo, que coloca no indivíduo a responsabilidade por seu sucesso ou fracasso, desconsiderando a divisão de classes sociais. Essa divisão, do nosso ponto de vista, é fruto do capitalismo, o qual, por intermédio das relações sociais, diferencia os indivíduos, não dando a todos as mesmas condições para o desenvolvimento de suas potencialidades, até mesmo a de se apropriar do conhecimento, e dessa forma procura encontrar as causas das dificuldades de aprendizagem no organismo do indivíduo, conforme explica Patto (1990).

Moysés e Collares (1997), ao realizaram uma pesquisa sobre o fracasso escolar, ouvindo opiniões de profissionais da educação e saúde acerca das causas do insucesso escolar, constataram que todos os indivíduos pesquisados, independentemente de sua área de atuação ou formação, continuavam explicando esse fenômeno como centrado no próprio aluno, sem ao menos considerarem o fracasso do sistema escolar. Do mesmo modo que se referem às causas centradas na criança, todos, independentemente da formação ou do campo de atuação, mencionavam 
problemas biológicos como causas para a não aprendizagem, apresentando como problemas as disfunções neurológicas e a desnutrição. Os psicólogos, ao encaminharem os alunos para psicoterapia, podem novamente contribuir para a individualização de problemas que são produzidos socialmente, conforme destacou Patto (1990) no estudo sobre o fracasso escolar.

No que tange às sugestões para o trabalho com alunos avaliados, foi possível verificar que 22 relatórios (61\%) não apresentam sugestões para o trabalho com os alunos. Assim, o relatório parece ter como finalidade apenas rotular esse aluno com alguma patologia, pois se ele não consegue aprender, é porque tem algum problema, seja este de ordem orgânica ou social. Ao tratar dos laudos psicológicos, Patto (1997) afirma que os laudos, geralmente, não têm bom-senso, são elaborados no mais absoluto senso-comum e acabam produzindo estigmas, justificando a exclusão escolar de quase todos os examinandos, os quais são reduzidos realmente a coisas portadoras de defeitos de funcionamento em algum componente da máquina psíquica. A linguagem utilizada é estereotipada. Patto (1997) comenta que a mesmice das frases, conclusões e recomendações nos traz à mente um carimbo, pois os laudos falam de uma criança abstrata. Embora haja orientações no Conselho Federal de Psicologia (2003) para a elaboração dos laudos, no sentido de que especifiquem, por exemplo, os instrumentos utilizados, a abordagem teórica que serviu de subsídio para a análise das informações, nem sempre as recomendações mínimas são seguidas.

No caso do aluno encaminhado para avaliação psicológica, muitas vezes também o professor e o psicólogo partem do princípio de que o examinando é portador de alguma anormalidade. Neste sentido, a Psicologia passa a olhar as crianças encaminhadas como doentes, buscando nelas seus defeitos. Muito pouco é apresentado a respeito das potencialidades dos alunos, sobre os mediadores que os alunos utilizam na resolução das tarefas, ou mesmo sobre seu nível de desenvolvimento próximo (VIGOTSKI, 2000; VYGOTSKI, 1995), aspectos considerados importantes no processo de avaliação baseado nos pressupostos da Psicologia Histórico-Cultural.

\section{CONSIDERaÇões Finais}

Conforme pudemos observar no decorrer deste trabalho, o processo de avaliação psicológica é algo complexo e necessita ser estudado e discutido no contexto educacional. A partir dos relatórios analisados, pudemos observar que no Estado do Paraná a psicometria é ainda bastante forte, com a utilização do teste psicológico formal para mensurar o QI; mas também pudemos notar que alguns psicólogos mencionaram: além do teste formal, utilizavam observações durante o processo de avaliação, bem como a análise das atividades acadêmicas escolares e a anamnese, o que demonstra que as avaliações não estão se restringindo apenas aos testes psicométricos. Até mesmo a Secretaria de Educação do Estado orienta que a avaliação deve ser feita no contexto escolar e incluir a avaliação psicopedagógica, a ser realizada pelo profissional pedagogo e pelo psicólogo. Neste sentido, o psicólogo pode estar ocupando esse espaço para superar 
a avaliação tradicional, utilizando-se de uma avaliação pautada pela mediação, analisando o desenvolvimento infantil de um modo mais prospectivo, observando noções e conceitos que estão no nível de desenvolvimento próximo.

Vimos que a psicometria não deve ser a única maneira de avaliar uma criança, mas os psicólogos que trabalham na educação continuam fazendo uso dos testes psicométricos historicamente elaborados, contribuindo para um diagnóstico que classifica, rotula e culpa o aluno por não estar aprendendo. Vigotski e Luria (1996), assim como Lunt (1994), criticaram os testes psicológicos por avaliarem somente a quantidade de conhecimento ou habilidades que se encontram no nível real de desenvolvimento do aluno, sem considerar aquilo que está no nível de desenvolvimento próximo. Essa forma de avaliação não analisa o desenvolvimento prospectivamente e não considera o processo vivenciado pelo aluno durante o teste. Cumpre considerar, conforme afirma Souza (2000), os fatores intraescolares e o conjunto de relações institucionais, históricas, psicológicas e pedagógicas que constituem o cotidiano escolar e produzem a queixa do não aprendizado no aluno.

Como vivemos numa sociedade em que tudo precisa ser rápido, é muito mais útil e fácil realizar um teste psicométrico do que analisar todo o contexto históricosocial em que a criança se encontra inserida. É esse o comportamento que muitas vezes é exigido do psicólogo: fazer avaliação em um número elevado de alunos, de forma rápida e objetiva. Consideramos que os resultados mostrados nos testes pouco contribuem para o trabalho pedagógico a ser desenvolvido com esses alunos avaliados, servindo apenas para enquadrar essas crianças, isolando-as de seu meio social. Uma criança diagnosticada como alguém que tem inteligência abaixo da média do esperado para sua idade cronológica e experiência, muitas vezes passa a ser vista como alguém que não tem capacidade para se desenvolver e precisa ser separada das crianças ditas "normais", aquelas que se encontram, segundo o teste psicométrico, com a inteligência esperada para sua idade cronológica.

Quando colocamos na criança a culpa pelo seu não aprendizado, deixamos de considerar fatores intraescolares como condições de ensino na escola, metodologias de trabalho e recursos disponíveis para promover a superação das dificuldades no processo ensino-aprendizagem; assim como deixamos de refletir sobre as políticas públicas na área de educação, no que se refere à formação e valorização do trabalho docente, como um fator que influencia o sucesso escolar. Deixamos, também, entre outros pontos relacionados a condições subjetivas e objetivas, de compreender as dificuldades no processo de escolarização e de considerar a divisão de classe em uma sociedade capitalista, que não disponibiliza igualitariamente o acesso dos alunos ao conhecimento e a formas de se apropriar daquilo que os homens já produziram em várias ciências.

Diante dos resultados apresentados, não podemos deixar de mencionar que, tanto na literatura como em algumas situações observadas nos relatórios, há um movimento em busca da superação da avaliação psicométrica tradicional. Tais contradições, presentes na sociedade, ao mesmo tempo em que buscam manter uma visão ideológica, criam possibilidades de superá-la. Não obstante, apesar 
desses avanços, muito ainda precisamos fazer em prol do acesso de todos aos conhecimentos produzidos pelos homens, de forma a promover o desenvolvimento máximo das potencialidades dos alunos, apresentem eles deficiência ou não.

Facci, Tuleski e Eidt (2006) destacam que o ensino deve focar no trabalho com conhecimentos científicos, a fim de desenvolver as funções psicológicas superiores. Estas, em um processo de avaliação, necessitam ser investigadas numa perspectiva histórica. Assim sendo, o principal aspecto do método de análise psicológica proposto por autores da Psicologia Histórico-Cultural - perspectiva que consideramos importante adotar na intervenção do psicólogo escolar - é estudar a totalidade, as propriedades e funções das partes que a integram, a partir das particularidades que a determinam e com as quais se relacionam. Para isso, é de extrema urgência e necessidade resgatar a função da escola como um espaço educativo e humanizador, adotando-se uma filosofia que possibilite compreender o processo de desenvolvimento humano como histórico e social, levando em consideração a escola e a sociedade em que a criança avaliada se encontra inserida. Se na Psicologia Histórico-Cultural se entende que as funções psicológicas superiores se desenvolvem a partir da apropriação da cultura, necessário se faz analisar as oportunidades que aquele aluno que está sendo avaliado teve para se apropriar dos conhecimentos e se desenvolver psicologicamente. Compreendemos, assim, a partir da Psicologia Histórico-Cultural, que uma avaliação psicológica pode tornar-se importante para auxiliar na prática pedagógica, fornecendo elementos que auxiliem o professor na transmissão-apropriação dos conhecimentos.

\section{NoTAS}

${ }^{1}$ Primi (2003) afirma que há décadas existe uma preocupação da Psicologia em compreender a natureza da inteligência. Ao consultar a base de dados PsycINFO no período de 1887 até 2002, o autor menciona que localizou 18.400 artigos que continham a palavra inteligência no título.

${ }^{2}$ Nos anos de 1970 a Teoria da Carência Cultural responsabilizava a criança pobre e sua família pelo insucesso na alfabetização. Não questionava o papel da escola na produção do fracasso escolar, apenas sugeria uma mudança curricular, a fim de ajustar a criança carente à sociedade e apresentar como soluções programas especiais que buscassem compensar suas deficiências. Segundo Patto (1987), no âmbito dessa teoria está a tese da diferença cultural como explicação para o fracasso escolar, pois essa tese afirmava que a escola era inadequada para as crianças carentes, já que professores da classe média se utilizavam de métodos destinados a crianças da classe favorecida. Os Núcleos Regionais de Ensino são unidades que estão diretamente ligadas à Secretaria de Estado da Educação do Paraná, atuando em várias regiões do Estado. Eles acompanham a implantação e execução das políticas educacionais do Governo do Estado do Paraná no âmbito das escolas que fazem parte de sua jurisdição.

${ }^{4}$ Os relatórios não informam qual teste é utilizado, mas, considerando as orientações fornecidas nos cursos de Avaliação Psicoeducacional realizados por profissionais do Departamento de Educação Especial da Secretaria de Estado da Educação, podemos inferir que seja o WISC-III.

${ }^{5}$ No tocante aos relatórios emitidos por psicólogos, o Conselho Federal de Psicologia (CFP), por meio da Resolução CPF n. ${ }^{\circ}$ 007/2003, institui o Manual de Elaboração de Documentos Escritos, produzido pelo psicólogo, decorrente de avaliação psicológica. No caso do relatório psicológico, o CFP esclarece que esse relatório deve conter, no mínimo, cinco itens: identificação, descrição da demanda, procedimento, análise e conclusão. 


\section{REFERÊNCIAS}

AYACH, A. A.; CORRÊA, F. B. As políticas do Conselho Federal de Psicologia para avaliação psicológica. In: CONSELHO FEDERAL DE PSICOLOGIA CFP (Org.). Avaliação psicológica: diretrizes na regulamentação da profissão. Brasilia: CFP, 2010. p. 19-30.

CALEJON, L. M. C.; BEATÓN, G. A. Avaliação Psicológica, os testes e o diagnóstico explicativo. Piracicaba: G. E. Degaspari, 2002.

CARVALHO, T. O.; MARINHO-ARAUJO, C. M. Psicologia Escolar no Brasil e no Maranhão: percursos históricos e tendências atuais. Revista Semestral da Associação Brasileira de Psicologia Escolar e Educacional (ABRAPEE), São Paulo, v. 13, n. 1, p. 65-73, jan./fev. 2009.

CONSELHO FEDERAL DE PSICOLOGIA. Resolução CFP $n^{\circ}$ 007/2003. Brasilia, CFP, 2003.

FACCI, M. G. D.; ROMA, C. G.; SILVA, V. G.. A Avaliação psicológica na escola e a teoria histórico-cultural: difusão em periódicos de Psicologia. Encontro, Santo André, v. II, p. 79-94, 2007.

LESSA, P. V.; FACCI, M. G. D. A atuação do psicólogo no ensino público do Estado do Paraná. Psicologia Escolar e Educacional, Maringá, v. 15, n. 1, p. 131-141, jan./jun. 2011.

FACCI, M. G. D.; EIDT, N. M.; TULESKI, S. C. Contribuições da Teoria Histórico-Cultural para o processo de avaliação psicoeducacional. Revista Psicologia USP, São Paulo, v. 17, n. 1, p. 99-124, mar. 2006.

GOMES, W. B. Avaliação Psicológica no Brasil: Testes de Medeiros e Albuquerque. Avaliação Psicológica, Itatiba-SP, v. 3, n. 1, p. 59-68, jun. 2004.

LEONTIEV, A. N. O desenvolvimento do psiquismo. Lisboa: Livros Horizonte, 1978.

LINHARES, M. B. M.; ESCOLANO, A. C. M.; ENUMO, S. R. F. Avaliação Assistida: fundamentos teórico-conceituais e contribuições. In: LINHARES, M. B. M.; ESCOLANO, A. C. M.; ENUMO, S. R. F. (Org.). Avaliação assistida: fundamentos procedimentos e aplicabilidade. São Paulo: Casa do Psicólogo, 2006. p. 15-32.

LINHARES, M. B. M. Avaliação Assistida: fundamentos, definição, característica e implicações para a avaliação psicológica. Psicologia: Teoria e Pesquisa. Brasília, v. 11. n. 1, p.13-22, 1995. 
LUNT, I. A Prática da Avaliação. In: DANIELS, H. (Org.). Vigotsky em foco: pressupostos e desdobramentos. Campinas, SP: Papirus, 1994. p. 219-252.

LURIA, A. R. Fundamentos de Neuropsicologia. São Paulo: Universidade de São Paulo, 1981.

LURIA, A. R. Desenvolvimento Cognitivo. São Paulo: Ícone, 2008.

MACHADO, A. M. Avaliação Psicológica na educação: mudanças necessárias. In: TANAMACHI, E. R.; ROCHA, M. L.; SOUZA, M. P. R. (Org.). Psicologia e Educação: desafios teórico-práticos. São Paulo: Casa do Psicólogo, 2000. p. 143-167.

MEIRA, M. E. M. Psicologia Escolar: pensamento crítico e práticas profissionais. In: TANAMACHI, E. R.; ROCHA, M. L.; SOUZA, M. P. R. (Org.). Psicologia e Educação: desafios teórico-práticos. São Paulo: Casa do Psicólogo, 2000. p. 35-72.

MINDRISZ, R. K. A Tirania do QI: O Quociente de Inteligência na Caracterização do Indivíduo Deficiente Mental. 1994. Dissertação (Mestrado) - Pontifícia Universidade Católica de São Paulo, São Paulo, 1994.

MOYSÉS, M. A. A.; COLLARES, C. A. L. Inteligência abstraída, crianças silenciadas: as avaliações de inteligência. Revista Psicologia USP, São Paulo, v. 8, n. 1, p. 63-89, 1997.

PARANÁ (Estado). CEE. Deliberação nº 02/03, de 02/06/2003. Curitiba, 2003.

PATTO, M. H. S. Psicologia e Ideologia: uma introdução crítica a psicologia escolar. São Paulo: T. A. Queiroz, 1984.

PATTO, M. H. S. A produção do fracasso escolar: histórias de submissão e rebeldia. São Paulo: T. A . Queiroz, 1990.

PATTO, M. H. S. Para uma critica da razão psicométrica. Revista Psicologia USP, São Paulo, v. 8, n. 1, p. 47-62, 1997.

PRIMI, R. Avaliação psicológica no Brasil: fundamentos, situação atual e direções para o futuro. Psicologia Teoria e Pesquisa, Brasilia, v. 26, n. especial, p. 37-50, 2010. Disponível em: <http://www.revistaptp.unb.br/index.php/ptp/ article/view/477/81>. Acesso em: 04 nov. 2012. 
PRIMI, R. Inteligência: avanços nos modelos teóricos e nos instrumentos de medida. Avaliação Psicológica. Itatiba, SP, v. .2 , n. 1, p. 67-77, 2003. Disponível em: <http://pepsic.bvsalud.org/pdf/avp/v2n1/v2n1a08.pdf>. Acesso em: 04 nov. 2012.

SAVIANI, D. Pedagogia histórico-crítica: primeiras aproximações. 8. ed. Campinas: Cortez - Autores Associados, 2003.

SOUZA, M. P. R. Prontuários revelando os bastidores do atendimento psicológico à queixa escolar. In: SOUZA, B. P. (Org.). Orientação à queixa escolar. São Paulo: Casa do Psicólogo, 2007. v. 1, p. 27-58.

TAVARES, M. Da ordem social da regulamentação da avaliação psicológica e do uso dos testes. In: CONSELHO FEDERAL DE PSICOLOGIA - CFP (Org.). Avaliação psicológica: diretrizes na regulamentação da profissão. Brasília: CFP, 2010. p. 31-56.

VIGOTSKI, L. S. Teoria e Método em Psicologia. São Paulo: Martins Fontes, 1996.

VIGOTSKI, L. S. A construção do pensamento e da linguagem. São Paulo: Martins Fontes, 2000.

VYGOTSKI, L. S. Obras escogidas III. Madrid: Centro de Publicaciones del M.E.C. y Visor Distribuciones, 1995.

VYGOTSKY, L. S.; LURIA, A. R. Estudos sobre a história do comportamento: símios, homem primitivo e criança, Porto Alegre: Artes Médicas, 1996.

ZUCOLOTO, P. C. S. V. O médico higienista na escola: as origens históricas da medicalização do fracasso escolar. Revista Brasileira Crescimento e Desenvolvimento Humano, São Paulo, v. 17, n. 1, p. 136-145, abr. 2007. Disponível em: <http://www.revistasusp.sibi.usp.br/pdf/rbcdh/v17n1/13.pdf>. Acesso em: 04 nov. 2012.

Recebido em: 04 de abril de 2012 Aceito em: 21 de novembro de 2012 